IP Periodica Polytechnica

Transportation Engineering

46(4), pp. 207-214, 2018

https://doi.org/10.3311/PPtr. 11641

Creative Commons Attribution (i)

\title{
Exploring the Effects of University Campus Decentralization to Students' Mode Choice
}

\author{
Kornilia Maria Kotoula ${ }^{1 *}$, Alexandros Sialdas ${ }^{2}$, George Botzoris ${ }^{2}$, \\ Emmanouil Chaniotakis ${ }^{3}$, Josep Maria Salanova Grau ${ }^{1}$
}

RESEARCH ARTICLE

Received 17 April 2017; accepted 25 October 2017

\begin{abstract}
Mobility patterns and travel behavior aspects of students traveling to universities, are gaining attention, as the completion of such every day trips are rather complicated. University students form a social group, essentially autonomous in terms of mode choice decision making. Understanding the mode choice decision process, may reveal the most appropriate interventions for achieving sustainable transport goals. The current study aims to examine various aspects of university students' travel bahaviour such as travel distance, travel time, comfort and safety in the city of Xanthi, Greece. Moving a step forward, the paper provides a better understanding of students' travel patterns in two different environments due to the University relocation from an urban environment to a more isolated one. For this purpose, a questionnaire survey is conducted where students describe their travel habits before and after the relocation. In addition, students are given a choice set comprised of eight different factors hypothesized to internalize the effect of the relocation on mode choice for the trips to and from the University and they are asked to prioritize them ranking them from the most significant one to the least important. For the analysis two Multinomial Logit models are developed. The results verify initial considerations; distance and time are the most important factors for both cases while the use of public transport instead of walking increases the importance of economy and safety.
\end{abstract}

\section{Keywords}

students, travel behavior, mobility patterns, mode choice, alternative modes of transport

\footnotetext{
${ }^{1}$ Hellenic Institute of Transport/Centre for Research and Technology Hellas (HIT/CERTH), 6th km Charilaou-Thermi Road, Thessaloniki, 57001, Greece

${ }^{2}$ Democritus Thrace University, Department of Civil Engineering, Section of Transportation, Campus Kimmeria, 67100 Xanthi, Greece

${ }^{3}$ Technical University of Munich, Transportation Systems Engineering, Arcisstraße 21, D-80333, Munich, Germany

*Corresponding author, e-mail: nilia@certh.gr
}

\section{Introduction}

Mobility patterns and travel behavior aspects of students traveling to universities, colleges and institutions have garnered increasing attention, as the completion of such every day trips are rather complicated. University students form a social group, essentially autonomous in terms of mode choice decision making, while representing a vast percentage of the total travel demand. Thus, their mobility habits are considered as basic elements which need to be recorded and analyzed, in a comprehensible way for local authorities, urban, spatial, transport and university planners. Understanding the mode choice decision process, may allow them to proceed to the most appropriate interventions which will lead to the achievement of sustainable transport goals (Limanond et al., 2011). Thus, new sustainable policies may be proposed, adopted and implemented for the enhancement of alternative modes of transport such as public transport, walking and bicycling (Shannon et al., 2006), restricting thereby the use of private vehicle. According to Khattak et al. (2011), even though these students represent a large and significant proportion of the travelling public, they have not yet gained the relevant academic importance, as they are rather underrepresented in most travel behavior studies. In contrast, there are several previous studies (Timperio et al., 2006; Mitra and Buliung, 2012; McDonald, 2008; Noland et al., 2014; Zhang et al., 2017; Hatamzadej et al., 2017), already focused on primary and high school students' mode choice decision to and from school. The difference between the two cases is that underage students are entirely depended on their parents' decision regarding the transport mode they will use in order to complete a school trip (Ferreira et al., 2007), while university students decide on their own in most cases. In addition, the number of universities is significantly low in comparison to schools, which means that the concentration of travelers is higher and therefore the impact of the use of private cars stronger.

The objective of the current study is to investigate the behavioral change of students traveling to and from the University in the city of Xanthi, northeastern Greece, taking into account the location of the University (whether it is located inside or outside the city). The particularity of this study is the fact that the research takes into account the relocation of the 
University premises from the city's centre, to a location $5 \mathrm{~km}$ outside the urban area. For the research needs a questionnaire survey takes place based on students' mobility patterns. The study aims to examine various aspects of travel behavior such as travel distance, travel time, comfort and safety. Moving a step forward, this paper provides a better understanding of travel patterns in two campus environments (the urban before and the isolated after) using the same sample, a topic which so far has received minimum attention in the transportation field. The paper is structured as described below: firstly, a literature review is presented regarding the relevant research; following a description of the study subjects as well as the data sources is provided; the next section provides the basic empirical results which are discussed; finally, conclusions are provided and future directions of the present study are summarized.

\section{University students' travel behavior}

Limandon et al. (2011) examined the travel patterns of 130 students in a rural University of Thailand. Using t-test and ANOVA analysis, it was found out that both male and female students who own a private vehicle tend to execute all of their trips to and from the University with it, independently of the distance needs to be covered as well as the trip's duration. Moreover, the specific research concluded that the use of public transport reduces in favor of being a passenger on a friend's vehicle, despite the fact that the bus services are provided free to all students.

Whalen et al. (2013) examined the mode choice behavior of 1385 students travelling to McMaster University (Canada). For that purpose, a questionnaire survey was conducted and a multinomial logit model was calibrated, which confirmed initial perspectives; travel time has a negative impact on alternative transport modes (walking/ bicycling) and a positive one in case of private vehicle and bus use. Moreover, built environment features such as street density and sidewalk density empower the use of motorized transport modes (car/bus). Finally, as expected, owing a parking place increases the possibility of using a private vehicle.

A survey which took place in Los Angeles (USA) tried to assess the relationships between transport to/from University (active versus passive), with age (undergraduate vs graduate students), gender, distance, parking permit and students' residence type (Zhou, 2012). The survey was conducted in 508 students. The multinomial logit analysis showed that undergraduate students and female students are more likely to bike or walk, while the older students are those increasing the use of private vehicle. Moreover, as commute distance increases, car pooling and bus use also increase, while for once more parking permit is a basic factor which increases the levels of private car use.

Delmelle and Delmelle (2012) used a sample of 567 students in Idaho University (USA) and confirmed that the distance from University was a major determinant for mode choice decision. More specifically, walking was the favorable mode for those living within $2.5 \mathrm{~km}$ of the University premises whilst the use of private vehicle became more popular beyond that distance. Additionally, it was confirmed that weather conditions are a crucial factor in the mode choice decision making process, but only for males. More specifically, there was an observed variation in car usage between the winter and autumn months in males, while females did not exhibit behavioral changes throughout the year.

Davison et al. (2015) through their research highlighted significant cultural differences and complexities in travel behavior of students in the United Kingdom and Ireland. More specifically, it was found out that Northern Ireland students were significantly more car use depended, compared to students of other areas. Regarding the public transport systems usage, this was found more pronounced amongst Scottish students. In general, the research concluded that student car users were more likely to be female and older students.

Muromachi (2017) conducted a questionnaire survey in 351 University students, located in the Tokyo Metropolitan area and found out that that experience of past bicycle use during the High school period, affected the intention of future car use positively, while the use of rail services during the High school period, showed a statistically significant negative correlation.

Ripplinger et al. (2009), investigated attitudes and behaviors of the North Dakota State University students and found out that the students with access to automobiles use them to commute, while most of the other students use the bus for their daily trips to and from the University mainly for cost-savings and convenience. Using a mixed multinomial logit model, the study moved a step forward and found out that a possible fuel price increase, leads to bus ridership increase.

Finally, Zhan et al. (2016) used a web-based travel survey in order to obtain travel data regarding the students' mode choice patterns throughout eight Universities in three typical higher education cities in China. As expected, the male students choose to bike more frequently than female students who eventually choose public transit for their daily trips. Bicycle ownership seems to have a great impact on student mode choice, as the students owning a bicycle are more likely to use it. Moreover, the travel distance is the decisive factor of university students' mode choice, as walking to and from the university decreases rapidly with the increasing of travel distance.

A review of the samples and methodologies used in various surveys of university students' mode choice decision is presented in Table 1.

\section{Research design \\ 3.1 The case study}

The current research investigates travel patterns of students, studying at the Democritus University of Thrace (DUTh), at the Northeastern part of Greece. The University started operating during the academic year 1974-1975. Nowadays, overall 15.000 students are studying at DUTh, in eight Faculties and nineteen schools located in four different cities of Thrace. The 
Table 1 Literature findings on travel behaviour of university students

\begin{tabular}{|c|c|c|c|c|}
\hline Reference & $\begin{array}{c}\text { Sample (number of university } \\
\text { students) }\end{array}$ & $\begin{array}{l}\text { Transport modes } \\
\text { examined }\end{array}$ & Aspects examined and analyzed & Methodology \\
\hline $\begin{array}{l}\text { Limandon et al. } \\
(2010)\end{array}$ & $\begin{array}{c}\mathrm{n}=130 \\
\text { Suranaree University of Technology } \\
\text { (SUT), North-Eastern Thailand }\end{array}$ & car, motorcycle, bus & $\begin{array}{l}\text { car ownership, distance travelled, time } \\
\text { spent on travelling }\end{array}$ & t-test anova \\
\hline $\begin{array}{l}\text { Whalen et al. } \\
\text { (2008) }\end{array}$ & $\begin{array}{c}\mathrm{n}=1385 \\
\text { McMaster University, Hamilton, Canada }\end{array}$ & cycling, walking, car, bus & $\begin{array}{l}\text { travel time, built environment, parking } \\
\text { permit }\end{array}$ & $\begin{array}{l}\text { multinomial logit } \\
\text { model }\end{array}$ \\
\hline Zhou J. (2012) & $\begin{array}{c}\mathrm{n}=508 \\
\text { University of California, Los Angeles } \\
\text { (UCLA), USA }\end{array}$ & $\begin{array}{l}\text { cycling, walking, car, } \\
\text { carpooling, bus }\end{array}$ & $\begin{array}{l}\text { age, distance, parking permit, } \\
\text { residence type }\end{array}$ & $\begin{array}{l}\text { multinomial logit } \\
\text { model }\end{array}$ \\
\hline $\begin{array}{l}\text { Delmelle and } \\
\text { Delmelle (2012) }\end{array}$ & $\begin{array}{l}\qquad \mathrm{n}=567 \\
\text { University of Idaho, Moscow, USA }\end{array}$ & $\begin{array}{l}\text { cycling, walking, car, } \\
\text { carpooling, bus }\end{array}$ & $\begin{array}{c}\text { gender, distance, weather conditions, } \\
\text { traffic conditions }\end{array}$ & not specified \\
\hline $\begin{array}{l}\text { Davison et al. } \\
(2015)\end{array}$ & $\begin{array}{c}\mathrm{n}=1049 \\
17 \text { Universities } \\
\text { in United Kingdom and Ireland }\end{array}$ & cycling, walking, car, bus & gender, age, nationality & not specified \\
\hline $\begin{array}{l}\text { Muromachi Y. } \\
\text { (2013) }\end{array}$ & $\begin{array}{c}\mathrm{n}=351 \\
7 \text { Universities in Tokyo }\end{array}$ & cycling, rail & $\begin{array}{c}\text { experiences of past school travel mode } \\
\text { choices }\end{array}$ & $\begin{array}{l}\text { ordered choice } \\
\text { model }\end{array}$ \\
\hline $\begin{array}{l}\text { Ripplinger et al. } \\
\text { (2009) }\end{array}$ & $\begin{array}{l}\qquad \mathrm{n}=75 \\
\text { fourth year students North Dakota State } \\
\text { University (NDSU) }\end{array}$ & car, public transit & $\begin{array}{c}\text { car ownership, cost-savings, } \\
\text { convenience }\end{array}$ & $\begin{array}{l}\text { mixed multinomial } \\
\text { logit model }\end{array}$ \\
\hline $\begin{array}{l}\text { Zhan et al. } \\
\text { (2014) }\end{array}$ & $\begin{array}{l}\qquad \mathrm{n}=1343 \\
8 \text { Universities in China Beijing, } \\
\text { Shanghai, Nanjing }\end{array}$ & $\begin{array}{c}\text { walking, cycling, public } \\
\text { transit }\end{array}$ & $\begin{array}{l}\text { gender, student grade, school location } \\
\text { city, public transit coverage ratio, } \\
\text { family income, bicycle ownership }\end{array}$ & $\begin{array}{l}\text { hierarchical tree- } \\
\text { based regression } \\
\text { model }\end{array}$ \\
\hline
\end{tabular}

case study focuses in the city of Xanthi, where five Faculties of Engineering operate. Taking into account the recent relocation of the University premises from the city center to a more sparsely populated area $5 \mathrm{~km}$ outside the urban environment as depicted in Fig. 1, the study examines various aspects of travel behavior such as travel distance, travel time, comfort and safety in two different environments (urban-isolated).

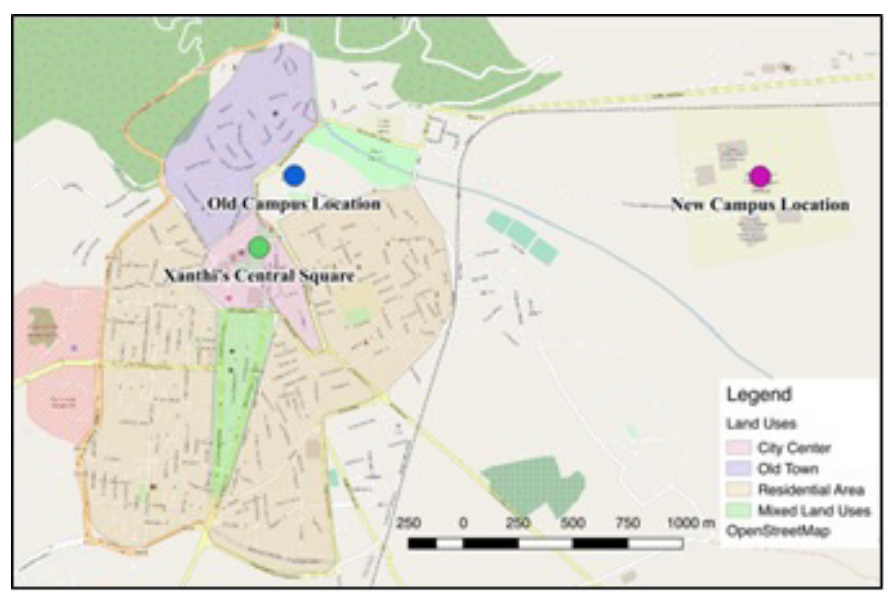

Fig. 1 The old and new University location in the city of Xanthi.

Regarding the five Faculties, the three of them have already been relocated to the new premises numbering approximately 2000 students, while the other two are still operating at the old premises, numbering 1000 students. The current survey was designed and conducted in students of the Faculty of Civil
Engineering, relocated on September 2016 and numbering approximately 800 students. The minimum sample size was defined based on the following statistical method (Johnson and Wichern, 1992):

$$
n \geq N \cdot\left[1+\frac{N-1}{p \cdot(1-p)} \cdot\left(\frac{d}{z_{a / 2}}\right)^{2}\right]^{-1}
$$

where

$\mathrm{N}$ : the number of total population.

$\mathrm{n}$ : size of sample, the number of individuals required in order the required level of precision to be achieved.

p: a probability parameter estimating the chance that the sample contains a specific characteristic. Parameter $p$ is an estimation of the proportion of individuals (with a specific characteristic) falling into the group for which we are interested within the population. If no previous experience exists, then a value $\mathrm{p}=50 \%$ is considered as the worst case.

$\mathrm{d}$ : the acceptable error that we are willing to accept or tolerate (in our research $\pm 5 \%$ ). It describes how close the answer of the sample is to the true value of the population. The smaller the margin of error is, the closer the findings of the survey are to the reality.

$\mathrm{z}_{\alpha / 2}$ : parameter related on the confidence level which measures how certain we can be that the sample reflects the population, within the acceptable error $d$. It takes the value 1.96 for confidence level $95 \%$. 
Based on Eq. (1) for the case examined, 235 questionnaires were collected. The sample included students from all years of study, except those who were attending their first year (approximately 150). The reason for not including them in the research is that they did not experience the relocation of the University premises and therefore their travel habits would only concern the new location.

According to the aim of this research, a questionnaire was designed. The first part of the questionnaire included students' socio-demographic characteristics (gender, year of study, car ownership, etc.). At the second part, students were asked to describe their travel habits before and after the University relocation. Moreover, students were given a choice set comprised of eight different factors hypothesized to internalize the effect of the relocation on mode choice for the trips to and from the University and they were asked to prioritize them (taking into account both the before and after University relocation situation), ranking them from the most significant one to the least important. In the third part, students who mainly used the public transport system for their trips were asked to evaluate it based on 13 qualitative factors covering all the phases of the trip (before the trip, on the station, en route).

\subsection{Infrastructure and transport mode choices in the city of Xanthi}

The city of Xanthi (Fig. 1) is divided in the west part where the old and the modern town are located and the east part that boasts a rich natural environment. The west part is the most developed one, as it concentrates most of the daily activities. According to the 2011 Census data, the city accommodates approximately 56,100 inhabitants within an area of $153,116 \mathrm{~km}^{2}$. Among the most severe problems faced in Xanthi today is congestion. Despite the significant impacts of the economic crisis which has resulted to reduced activities and subsequently reduced demand for transport, the city of Xanthi is still facing severe congestion problems, mainly due to the extensive use of private car. Regarding its topology, Xanthi is a flat city with no sharp slopes, a fact that favors the use of walking and bicycle. However, an organized and coherent cycle network does not exist. Residents and visitors willing to bike within the urban and interurban environment or to and from the University are obliged to use the road network. Moreover, not any bike sharing system operates in the city. Regarding the public transportation system, this is provided by one bus operator, covering the city by operating eight different lines, one of which connects the city center with the new University location. The specific line is provided free to all students, every one hour, from early morning to late evening. The route from the center to the University differs from the route serving the opposite trips, due to the fact that the latter is considerably more length extended. Lastly, there is not a consistent walking network for students who choose to walk from the city center to the new University location.

\section{Research analysis}

The analysis performed aims at identifying the magnitude of the role that every qualitative parameter asked in the questionnaire plays. Different methods are deployed starting from the cross-classification of change of mode that allows for the identification of the percentage of change, giving an interesting investigation of the willingness to change modes. Additionally, a quadrant analysis is performed examining thirteen qualitative factors in order useful conclusions to arise regarding the current public transport system operation. Finally, the application of Discrete Choice Analysis takes place as a metric concerning the changes that relocation can bring to the perception of travel disutility. It should be noted that the models produced are just indicative of the magnitude of the role that each parameter has to the choice of mode. By no means, can they be used for prediction of choices as they are bounded to the limited number of independent variables and parameters and their qualitative nature.

\section{Results of the research}

Regarding the travel modes students used for their daily trips to and from the University, these can be classified in three groups:

a) Active transportation: walking and bicycling.

b) Public transit: local public transportation system (bus).

c) Motorized cars: private car, motorbike, taxi, private car passenger.

Based on this classification students were asked to indicate on a Revealed Preference concept the mode used more frequently before and after the relocation.

Some interesting findings from this analysis is that students who used a private car for their trip to and from the University did not change their behavior, while students used to walk to the University now tend to take the bus as the distance is rather longer. Table 2 summarizes the changes in the transportation mode as reported in the survey. As depicted, the most significant change is observed on students used to walk to and from the University in the past (66\%), while nowadays are mostly using the public transport system $(42 \%)$ or private vehicles $(17 \%$ as a driver and passenger combined). This can be actually explained based on the fact that as found from the questionnaire, most students $(84 \%)$ are captive users that do not own a car.

In order to assess the factors that determine the decision to retain a mode choice or change to another one, the questionnaire included questions where students were asked to hierarchise the factors that affected their choices. As the goal of the questionnaire was to grasp the changing behavior of a changing situation, the analysis focuses on the changes and not on the absolute values. In Fig. 2 the first, second and third preferences are presented. As it is clearly evidenced, the factors affecting the choices do not change dramatically, with the first and second factors to predominantly reflect the distance and time needed to reach the 
University campus, while after the relocation, the economic effect of commuting to the campus seems to increase in the students' preferences. This is mainly attributed to the fact that the location the campus relocated is not in a walkable range from the city center, where most students who experience the relocation used to dwell. Consequently, the use of public transport instead of walking increased the importance of the economy and safety when choosing the transportation mode, factors seemed to be less important when the University was located within the city center.

Table 2 Descriptive changes in mode choice due to the University relocation

\begin{tabular}{|c|c|c|c|c|c|c|c|c|}
\hline $\begin{array}{l}\text { Mode choice } \\
\text { before and } \\
\text { after University } \\
\text { relocation }\end{array}$ & $\begin{array}{l}\dot{D} \\
: \\
\bar{E} \\
1 \\
\dot{E}\end{array}$ & 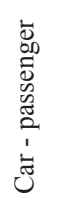 & $\stackrel{\mathscr{D}}{\tilde{D}}$ & $\underset{\widetilde{E}}{\overrightarrow{\widetilde{E}}}$ & $\begin{array}{l}\frac{0}{0} \\
\stackrel{0}{0}\end{array}$ & 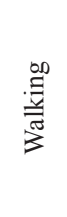 & $\begin{array}{l}\frac{\mathscr{y}}{03} \\
\frac{0}{0} \\
\stackrel{0}{0}\end{array}$ & 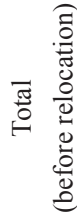 \\
\hline Car - driver & $6 \%$ & $0 \%$ & $0 \%$ & $0 \%$ & $0 \%$ & $0 \%$ & $0 \%$ & $6 \%$ \\
\hline Car - passenger & $0 \%$ & $0 \%$ & $0 \%$ & $0 \%$ & $0 \%$ & $0 \%$ & $0 \%$ & $0 \%$ \\
\hline Bus & $1 \%$ & $0 \%$ & $10 \%$ & $0 \%$ & $0 \%$ & & $0 \%$ & \\
\hline Taxi & $0 \%$ & $0 \%$ & $1 \%$ & $0 \%$ & $0 \%$ & $0 \%$ & $0 \%$ & $1 \%$ \\
\hline Bike & $0 \%$ & $0 \%$ & $1 \%$ & $0 \%$ & $2 \%$ & $1 \%$ & $0 \%$ & $4 \%$ \\
\hline Walking & $8 \%$ & $9 \%$ & $42 \%$ & $3 \%$ & $1 \%$ & $3 \%$ & $0 \%$ & $66 \%$ \\
\hline Motorbike & $0 \%$ & $0 \%$ & $0 \%$ & $0 \%$ & $0 \%$ & $0 \%$ & $2 \%$ & $2 \%$ \\
\hline $\begin{array}{l}\text { Total (after } \\
\text { relocation) }\end{array}$ & $15 \%$ & $9 \%$ & $54 \%$ & $3 \%$ & $3 \%$ & $10 \%$ & $2 \%$ & \\
\hline
\end{tabular}

Table 3 below presents two Multinomial Logit models that are estimated based on the ranking of the mobility related factors introduced in the questionnaire, in order to estimate the magnitude of change in terms of their ranking concerning commuting to University. It should be noted that the models estimated are only presented as a proxy of the effect that a relocation has. Thus, the results cannot be interpreted in the form of traditional choice models due to the lack of the required parameters for a proper estimation. It is believed however, that their comparison allows for a better understanding of the effect that the relocation had to students' choices.

As it can be directly observed, the estimators of walking and car passenger are significantly related to the distance, comfort and safety. This can directly be attributed to the longer distance required to commute to the new location as well as the fact that all the available paths connecting the relocated University and the city center are not pedestrian-friendly and pass from isolated locations where walking is scarce.

The significance of most variables in the car passenger choice increased, while significance of most variables in the walking choice is much lower. In the walking choice only the significance of comfort increased, since is almost unfeasible to walk to the University for the students living in the city center. The lack of changes on the car driver choice may be due to the fact that the ones traveling by car to the old location continue
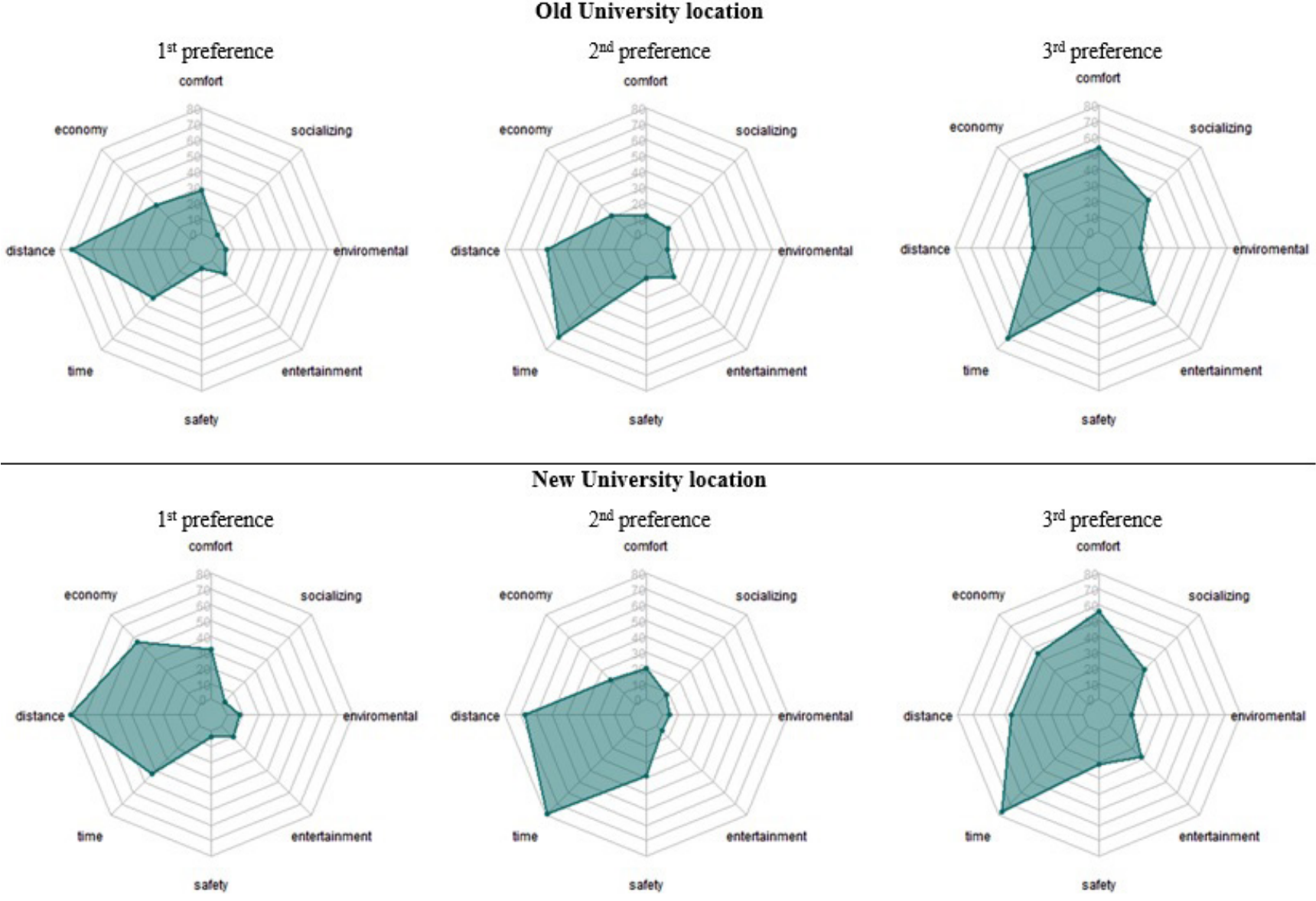

Fig. 2 Comparison of factors affecting students' decision before and after the University relocation. 
traveling by car to the new location. Maybe the inclusion of questions about parking allowance would have changed significantly with the new location since in the city center is hard to park while in the new location is much easier.

With regards to the variables, time and safety present the largest variations in their significance, especially for walking and public transport modes. Year and gender also present important variations in their significance.

Regarding the quadrant analysis, the results were based on the students' judgment concerning the importance and significance of thirteen key factors determining the operation of a public transport system. The quadrant analysis revealed some basic issues in the quality offered. As depicted in Fig. 3, all the examined factors are especially significant according to the students' responds as they have been ranked over 3.5. Regarding the levels of satisfaction, it seems that in total seven are the factors which are inadequately satisfied (ranked under 3 ); routes frequency, comfort at the bus stop, bus capacity (congestion), cleanliness inside the bus, seat comfort, driver behavior, and passenger safety at the bus stop. Thus, these are the factors recommended to be taken into account from the public transport operator, in order to proceed to the relevant interventions for the system's upgrade.

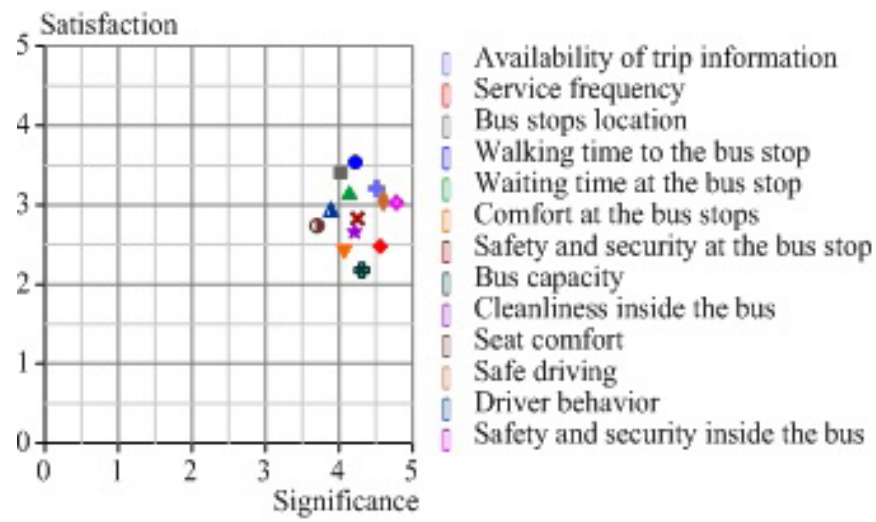

Fig. 3 Quadrant analysis results regarding thirteen qualitative factors assessing the public transport system in the city of Xanthi.

Table 3 Comparison of students' travel patterns regarding the old and the new University location

\begin{tabular}{|c|c|c|c|c|c|c|c|c|}
\hline \multirow{2}{*}{ Variable } & \multicolumn{4}{|c|}{ Old University location } & \multicolumn{4}{|c|}{ New University location } \\
\hline & Estimate & Std. Error & t-value & $\operatorname{Pr}(>|t|)$ & Estimate & Std. Error & t-value & $\operatorname{Pr}(>|t|)$ \\
\hline Bus: (intercept) & $-1.97 \cdot 10^{5}$ & $7.27 \cdot 10^{8}$ & -0.0003 & 0.999784 & $1.71 \cdot 10^{5}$ & $9.55 \cdot 10^{8}$ & 0.0002 & 0.999857 \\
\hline Car driver: (intercept) & $1.35 \cdot 10^{5}$ & $8.07 \cdot 10^{8}$ & 0.0002 & 0.999867 & $1.53 \cdot 10^{5}$ & $1.05 \cdot 10^{9}$ & 0.0001 & 0.999884 \\
\hline Car passenger: (intercept) & $2.22 \cdot 10^{6}$ & $2.56 \cdot 10^{9}$ & 0.0009 & 0.999309 & $2.02 \cdot 10^{5}$ & $1.16 \cdot 10^{9}$ & 0.0002 & 0.999861 \\
\hline Motorbike: (intercept) & $1.04 \cdot 10^{7}$ & $3.20 \cdot 10^{9}$ & 0.0033 & 0.997402 & $5.80 \cdot 10^{5}$ & $2.08 \cdot 10^{9}$ & 0.0003 & 0.999778 \\
\hline Taxi: (intercept) & $-3.78 \cdot 10^{5}$ & $8.54 \cdot 10^{8}$ & -0.0004 & 0.999647 & $-2.23 \cdot 10^{5}$ & $1.03 \cdot 10^{9}$ & -0.0002 & 0.999827 \\
\hline Walking: (intercept) & $7.73 \cdot 10^{4}$ & $7.26 \cdot 10^{4}$ & 1.0648 & 0.286967 & $1.87 \cdot 10^{5}$ & $9.55 \cdot 10^{8}$ & 0.0002 & 0.999844 \\
\hline Walking: gender female & $1.19 \cdot 10^{4}$ & $8,38 \cdot 10^{3}$ & 1.4242 & 0.154399 & $6.42 \cdot 10^{3}$ & $9.54 \cdot 10^{3}$ & 0.6735 & 0.500619 \\
\hline Bus: year & $3.11 \cdot 10^{3}$ & $3.01 \cdot 10^{3}$ & 1.0318 & 0.302161 & $-1.03 \cdot 10^{3}$ & $3.28 \cdot 10^{3}$ & -0.3122 & 0.754906 \\
\hline Bus: comfort & $2.97 \cdot 10^{3}$ & $3.11 \cdot 10^{3}$ & 0.9530 & 0.340600 & $5.33 \cdot 10^{3}$ & $3.89 \cdot 10^{3}$ & 1.3708 & 0.170422 \\
\hline Car driver: comfort & $-2.72 \cdot 10^{4}$ & $1.25 \cdot 10^{4}$ & -2.1806 & 0.029212 & $-9.86 \cdot 10^{3}$ & $5.28 \cdot 10^{3}$ & -1.8677 & 0.061801 \\
\hline Car passenger: comfort & $-9.40 \cdot 10^{4}$ & $1.03 \cdot 10^{8}$ & -0.0009 & 0.999270 & $-1.32 \cdot 10^{4}$ & $5.22 \cdot 10^{3}$ & -2.5208 & 0.011708 \\
\hline Walking: comfort & $-1.65 \cdot 10^{2}$ & $2.62 \cdot 10^{3}$ & -0.0630 & 0.949778 & $4.51 \cdot 10^{3}$ & $3.96 \cdot 10^{3}$ & 1.1395 & 0.254497 \\
\hline Taxi: economy & $1.43 \cdot 10^{4}$ & $1.11 \cdot 10^{4}$ & 1.2879 & 0.197769 & $2.19 \cdot 10^{4}$ & $8.63 \cdot 10^{3}$ & 2.5430 & 0.010991 \\
\hline Bus: distance & $-4.63 \cdot 10^{3}$ & $3.36 \cdot 10^{3}$ & -1.3768 & 0.168570 & $-2.53 \cdot 10^{3}$ & $3.66 \cdot 10^{3}$ & -0.6921 & 0.488864 \\
\hline Car passenger: distance & $-6.29 \cdot 10^{3}$ & $1.72 \cdot 10^{8}$ & 0 & 0.999971 & $-5.10 \cdot 10^{3}$ & $4.56 \cdot 10^{3}$ & -11.186 & 0.263311 \\
\hline Walking: distance & $-6.70 \cdot 10^{3}$ & $2.81 \cdot 10^{3}$ & -2.3875 & 0.016965 & $5.93 \cdot 10^{2}$ & $3.39 \cdot 10^{3}$ & 0.1748 & 0.861259 \\
\hline Bus: safety & $-1.46 \cdot 10^{4}$ & $3.97 \cdot 10^{3}$ & -3.6781 & 0.000235 & $-5.84 \cdot 10^{3}$ & $3.74 \cdot 10^{3}$ & -1.5606 & 0.118615 \\
\hline Car driver: safety & $-2.71 \cdot 10^{4}$ & $9.95 \cdot 10^{3}$ & -2.7255 & 0.006420 & $-1.32 \cdot 10^{4}$ & $4.63 \cdot 10^{3}$ & -2.8508 & 0.004361 \\
\hline Taxi: safety & $-2.50 \cdot 10^{4}$ & $1.26 \cdot 10^{4}$ & -1.9851 & 0.047133 & $3.01 \cdot 10^{3}$ & $7.15 \cdot 10^{3}$ & 0.4210 & 0.673728 \\
\hline Walking: safety & $-7.28 \cdot 10^{3}$ & $3.43 \cdot 10^{3}$ & -2.1196 & 0.034041 & $-7.80 \cdot 10^{2}$ & $3.61 \cdot 10^{3}$ & -0.2161 & 0.828941 \\
\hline Walking: time & $9.41 \cdot 10^{3}$ & $4.58 \cdot 10^{3}$ & 2.0552 & 0.039855 & $2.82 \cdot 10^{3}$ & $4.67 \cdot 10^{3}$ & 0.6036 & 0.546089 \\
\hline Bus: socializing & $-4.79 \cdot 10^{3}$ & $3.91 \cdot 10^{3}$ & -1.2234 & 0.221189 & $-2.84 \cdot 10^{3}$ & $3.41 \cdot 10^{3}$ & -0.8340 & 0.404299 \\
\hline Car driver: socializing & $-1.03 \cdot 10^{4}$ & $7.27 \cdot 10^{3}$ & -1.4198 & 0.155657 & $-2.78 \cdot 10^{3}$ & $4.31 \cdot 10^{3}$ & -0.6453 & 0.518749 \\
\hline Car passenger: socializing & $-7.90 \cdot 10^{4}$ & $1.24 \cdot 10^{8}$ & -0.0006 & 0.999493 & $-1.07 \cdot 10^{4}$ & $4.17 \cdot 10^{3}$ & -2.5647 & 0.010327 \\
\hline Taxi: socializing & $1.01 \cdot 10^{4}$ & $1.17 \cdot 10^{4}$ & 0.8694 & 0.384647 & $9.59 \cdot 10^{3}$ & $7.55 \cdot 10^{3}$ & 1.2701 & 0.204049 \\
\hline Walking: socializing & $-4.90 \cdot 10^{3}$ & $3.46 \cdot 10^{3}$ & -1.4168 & 0.156545 & $1.59 \cdot 10^{3}$ & $3.38 \cdot 10^{3}$ & 0.4693 & 0.638833 \\
\hline
\end{tabular}




\section{Conclusion}

The present paper analyzed travel patterns characteristics of students at Democritus University of Thrace, located in the city of Xanthi, Northeastern Greece, in a combination of qualitative and quantitative analysis. A questionnaire survey was conducted on a sample of 235 students studying in the Faculty of Civil Engineering. The study examined travel patterns, taking into account the relocation of the University premises from the center of the city (urban environment) to a more isolated area. The analysis performed aimed at identifying the magnitude of the role that every qualitative parameter asked in the questionnaire plays. Different methods were deployed starting from the cross-classification of change of mode that allows for the identification of the percentage of change, giving an interesting investigation of the willingness to change modes. Additionally, the application of Discrete Choice Analysis took place as a metric concerning the changes that relocation could bring to the perception of travel disutility. Finally, a quadrant analysis was performed examining thirteen qualitative factors in order useful conclusions to arise regarding the current public transport system operation.

Some interesting findings from the analysis is that students who used a private car for their travel to and from the University did not change their behavior. The most significant variation was observed on students used to walk to and from the University in the past, while nowadays are mostly using the public transport system or private vehicles, due to the fact that the distance is now longer.

In order to assess the factors that determine the decision to retain a mode choice or change to another one, the questionnaire included questions where students were asked to hierarchize the factors that affected their choices. The research concluded that the factors affecting the choices did not change dramatically, with the first and second factors to predominantly reflect the distance and time needed to reach the University campus, while after the relocation, the economic effect of commuting to the campus seemed to increase in the students' preferences. Consequently, the use of public transport instead of walking increased the importance of the economy and safety when choosing the transportation mode, factors that seemed to be less important when the University was located within the city center.

Finally the quadrant analysis, showed that all the examined factors were especially significant, while routes frequency, comfort at the bus stop, bus capacity, cleanliness inside the bus, seat comfort, driver behavior, and passenger safety at the bus stop were inadequately satisfied.

In conclusion, a redevelopment of the area around the new University location (construction of pedestrian and bicycle paths) as well as the upgrade of the provided public transport system services could result in higher transit and pedestrian traffic. This possibility is suggested by the authors to be further examined in the near future, by investigating the willingness of students to walk, bike or commute by public transport in case significant interventions will be developed. Taking into account the results of the proposed investigation, the local authorities in full cooperation with urban, transport and university planners will be able to shape a strategic plan in order to promote the use of sustainable transport modes among university students, contributing thereby to an overall behavioral change in mode choice decision.

\section{References}

Davison, L., Ahern, A., Hine, J. (2015). Travel, transport and energy implications of university-related student travel: A case study approach. Transportation Research Part D: Transport and Environment. 38, pp. 27-40. https://doi.org/10.1016/j.trd.2015.04.028

Delmelle, E. M., Delmelle, E. C. (2012). Exploring spatio-temporal commuting patterns in a University environment. Transport Policy. 21, pp. 1-9. https://doi.org/10.1016/j.tranpol.2011.12.007

Ferreira, I., van der Horst, K., Wendel-Vos, W., Kremers, S., van Lenthe, F.J., Brug, J. (2007). Environmental correlates of physical activity in youth A review and update. Obesity Reviews. 8(2), pp. 129-154. https://doi.org/10.1111/j.1467-789X.2006.00264.x

Hatamzadej, Y., Habibian, M., Khodaii, A. (2017). Effective factors in walking mode choice of different age groups for school trips. Transportation Research Procedia. 25, pp. 2302-2313. https://doi.org/10.1016/j.trpro.2017.05.441

Johnson, R., Wichern, D. (1992). Multivariate Statistical Analysis. 3rd ed., Prentice-Hall, Englewood Cliffs (NJ).

Khattak, A., Wang, X., Son, S., Angello, P. (2011). Travel by university students in Virginia: is this travel different from travel by the general population. Transportation Research Record: Journal of the Transportation Research Board. 2255, pp. 137-145. https://doi.org/10.3141/2255-15

Limanond, T., Butsingkorn, T., Chermkhunthod, C. (2011). Travel behavior of university students who live on campus: a case study of a rural University in Asia. Transport Policy. 18(1), pp. 163-171. https://doi.org/10.1016/j.tranpol.2010.07.006

McDonald, N. C. (2008). Household interactions and children's school travel: the effect of parental work patterns on walking and biking to school. Journal of Transport Geography. 16(5), pp. 324-331. https://doi.org/10.1016/j.jtrangeo.2008.01.002

Mitra, R., Buliung, R. N. (2012). Intra-Household travel interactions, the built environment and school travel mode choice: an exploration using spatial models. Proceedings of the $91^{\text {st }}$ Annual Meeting of the Transportation Research Board, Washington, D.C.

Muromachi, Y. (2017). Experiences of past school travel modes by university students and their intention of future car purchase. Transportation Research Part A: Policy and Practice. 104, pp. 209-220. https://doi.org/10.1016/j.tra.2017.01.026

Noland, R., Park, H., Von Hagen, L. A., Chatman, D. G. (2014). A mode choice analysis of school trips in New Jersey. Journal of Transport and Land Use. 7(2), pp. 111-133. https://doi.org/10.5198/jtlu.v7i2.444

Ripplinger, D., Hough, J. A., Brandt-Sargent, B., Urban, S., Center, R. T. (2009). The Changing Attitudes and Behaviors of University Students Toward Public Transportation: Final Report (No. DP-222). Upper Great Plains Transportation Institute, North Dakota State University. Available from: http:/www.reconnectingamerica.org/assets/Uploads/ attitudesunivstupubtran2009.pdf [Accessed: 4th September 2017] 
Shannon, T., Giles-Corti, B., Pikora, T., Bulsara, M., Shilton, T., Bull, F. (2006). Active commuting in a university setting: assessing commuting habits and potential for modal change. Transport Policy. 13(3), pp. 240-253. https://doi.org/10.1016/j.tranpol.2005.11.002

Timperio, A., Ball, K., Salmon, J., Roberts, R., Giles-Corti, B., Simmons, D., Baur, L. A., Crawford, D. (2006). Personal, family, social, and environmental correlates of active commuting to school. American Journal of Preventive Medicine. 30(1), pp. 45-51. https://doi.org/10.1016/j.amepre.2005.08.047

Whalen, K. E., Páez, A., Carrasco, J. A. (2013). Mode choice of University students commuting to school and the role of active travel. Journal of Transport Geography. 31, pp. 132-142.

https://doi.org/10.1016/j.jtrangeo.2013.06.008
Zhan, G., Yan, X., Zhu, S., Wang, Y. (2016). Using hierarchical tree-based regression model to examine University student travel frequency and mode choice patterns in China. Transport Policy. 45, pp. 55-65. https://doi.org/10.1016/j.tranpol.2015.09.006

Zhang, R., Yao, E., Liu, Z. (2017). School travel mode choice in Beijing, China. Journal of Transport Geography. 62, pp. 98-110. https://doi.org/10.1016/j.jtrangeo.2017.06.001

Zhou, J. (2012). Sustainable commute in a car-dominant city: Factors affecting alternative mode choices among university students. Transportation Research Part A: Policy and Practice. 46(7), pp. 1013-1029. https://doi.org/10.1016/j.tra.2012.04.001 